\title{
The Role of Loneliness and Social Support in Adjustment to Loss: A Test of Attachment Versus Stress Theory
}

\author{
Wolfgang Stroebe and Margaret Stroebe \\ Utrecht University
}

\author{
Georgios Abakoumkin \\ University of Patras
}

\author{
Henk Schut \\ Utrecht University
}

\begin{abstract}
A longitudinal study of a matched sample of 60 recently widowed and 60 married men and women tested predictions from stress and attachment theory regarding the role of social support in adjustment to bereavement. Stress theory predicts a buffering effect, attributing the impact of bereavement on well-being to stressful deficits caused by the loss and assuming that these deficits can be compensated through social support. In contrast, attachment theory denies that supportive friends can compensate the loss of an attachment figure and predicts main effects of marital status and social support. Attachment theory further suggests that marital status and social support influence well-being by different pathways, with the impact of marital status mediated by emotional loneliness and the impact of social support mediated by social loneliness. Results clearly supported attachment theory.
\end{abstract}

One of the most widely shared truisms in bereavement research and practice is that support from family and friends is one of the most important moderators of bereavement outcome (e.g., Lopata, 1973; Sanders, 1993; W. Stroebe \& M. Stroebe, 1987; Stylianos \& Vachon, 1993). Yet, closer inspection of the bereavement literature suggests that the belief that social support can protect individuals against the deleterious effects of the death of a loved one is theoretically controversial and empirically not well supported. To clarify the role of social support in adjustment to bereavement, we first discuss predictions from the two major theoretical approaches relevant to bereavement: cognitive stress theory (e.g., Lazarus \& Folkman, 1984; W. Stroebe \& M. Stroebe, 1987) and attachment theory (Bowlby, 1979; Weiss, 1975, 1982). We then review previous research on the role of social support in adjustment to loss. Finally, we present data from our own longitudinal study that assess predictions from stress and attachment theory.

\section{The Role of Social Support in Adjustment to Loss: A Theoretical Analysis}

According to cognitive stress theories, critical life events such as bereavement are stressful because they require major

Wolfgang Stroebe, Margaret Stroebe, and Henk Schut, Research School of Psychology and Health, Utrecht University, Utrecht, The Netherlands; Georgios Abakoumkin, Department of Education, Psychology Section, University of Patras, Patras, Greece.

This research was financially supported through grants from the Deutsche Forschungsgemeinschaft.

Correspondence concerning this article should be addressed to Wolfgang Stroebe, Research School of Psychology and Health, Utrecht University, P.O. Box 80.140, 3508 TC Utrecht, The Netherlands. Electronic mail may be sent via the Internet to stroebe@fsw.ruu.nl. readjustment. The intensity of stress created by a life event depends on the extent to which the perceived demands of the situation tax or exceed an individual's coping resources, given that failure to cope leads to important negative consequences (Lazarus \& Folkman, 1984). Stress theory provides the theoretical underpinning for the "buffering model," which suggests that high levels of social support protect the individual against the deleterious impact of stress on health. According to Cohen and Wills (1985), there are two ways in which social support can buffer the individual against the negative impact of the stress experience. First, support can intervene between the stressful event and a stress reaction by attenuating or preventing a stress appraisal response. Second, adequate support may intervene between the experience of stress and the onset of the pathological response by eliminating the stress reaction or by directly influencing physiological processes. Whereas these two pathways reduce the individual's vulnerability to the impact of the stressful event, we propose a third way in which social support may affect individual stress response, namely, by aiding recovery. Thus, social support may also help individuals to recover more readily from the impact of the stressful life event.

The Deficit Model of Partner Loss was developed as an application of cognitive stress theory to bereavement (W. Stroebe \& M. Stroebe, 1987; W. Stroebe, M. Stroebe, K. Gergen, \& M. Gergen, 1980, 1982). On the basis of the interactional definition of stress, the deficit model offers an analysis of the situational demands characteristic of widowhood and of the coping resources needed to deal with these demands. Marital bereavement marks the end of a close mutual relationship, and the loss of a partner is likely to result in a number of deficits in areas in which the spouse had previously been able to rely on the partner. The Deficit Model suggests that the loss of a partner leads to deficits in areas that can broadly be characterized as loss of instrumental support, loss of validational support, loss of emotional support, and loss 


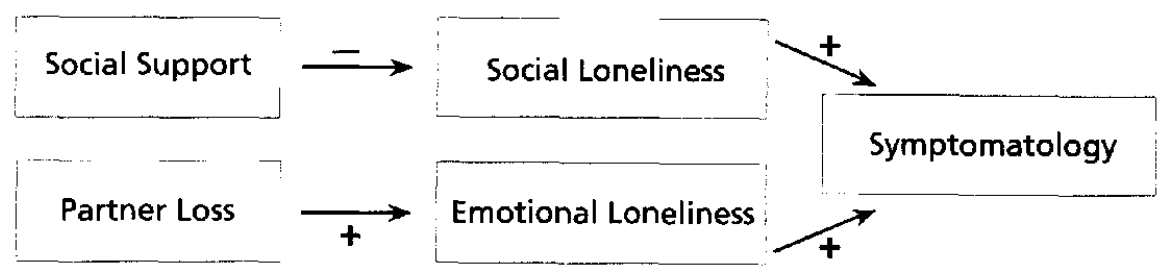

Figure 1. Attachment theory: The dual-path model.

of social contact support. The Deficit Model postulates that social support alleviates the stress of bereavement, but only to the extent to which it helps to replace the deficits created by the loss of a partner. ${ }^{1}$

It follows from the Deficit Model that bereaved individuals are in greater need of social support than married individuals. The model therefore predicts an interaction of social support and marital status on the level of psychological symptoms (i.e., buffering effect ). However, because it is unlikely that family and friends are able to alleviate completely the deficits caused by the loss of the partner, one would also expect a main effect of marital status on symptomatology.

In contrast, attachment theory rejects the notion that supportive friends can compensate for the loss of an attachment figure (Bowlby, 1969; Weiss, 1975). Bowlby (1969) proposed that the attachment figure, unlike other people in the social environment, was uniquely able to foster general feelings of security and that other people could not simply take over this function. He thus goes beyond optimal matching (e.g., Cutrona \& Russell, 1990), by not only requiring a match between the characteristic of stressful events confronting the individual and the form of social support that is beneficial in this context, but by stating categorically that this type of social support can only be provided by one specific type of person.

Weiss ( 1975 ) elaborated these ideas in his relational theory of loneliness, in which he drew a fundamental distinction between emotional and social loneliness and argued that the two types of loneliness cannot compensate for each other: The loneliness of emotional isolation appears in the absence of a close emotional attachment and can only be remedied by the integration of another emotional attachment or the reintegration of the one that had been lost. Those experiencing this form of loneliness are apt to experience a sense of utter aloneness, whether or not the companionship of others is in fact accessible (Weiss, 1975). Thus, according to attachment theory, social support from relatives and friends cannot compensate for the major deficit caused by bereavement, namely, the loss of an attachment figure. However, social support should help with a second type of loneliness, namely, the loneliness of social isolation. Social loneliness is associated with the absence of an engaging social network, and this absence can only be remedied by access to such a network. The dominant feeling of this type of loneliness is boredom, together with feelings of marginality (Weiss, 1975).

Attachment theory thus suggests that marital status and social support influence well-being by distinctly different pathways, with the impact of marital status being mediated by emotional loneliness and the impact of social support by social loneliness (Figure 1). According to this Dual-Path Model, one would predict main effects of marital status and social support on measures of symptomatology, but no interaction. Because each of these main effects is assumed to be mediated by a different type of loneliness, one would further expect marital status to affect emotional but not social loneliness and social support to affect social but not emotional loneliness. Finally, one would expect that control for emotional loneliness should reduce or eliminate the impact of marital status on symptomatology, whereas control for social loneliness should reduce or eliminate the effect of social support on symptom levels.

The two major theories of bereavement outcome thus make different and partly contradictory predictions about the role of social support in adjustment to loss. Consistent with popular beliefs about the helpfulness of social support to the bereaved, cognitive stress theory predicts a Social Support $\times$ Marital Status interaction on symptomatology (i.e., buffering effect) in addition to a main effect of marital status. In contrast, attachment theory predicts main effects of both marital status and social support on levels of symptoms, but no interaction. It further suggests that these two main effects on symptomatology are mediated by different types of loneliness. These predictions have not yet been addressed by empirical research.

\section{The Role of Social Support in Adjustment to Loss: A Review of the Evidence}

Guided by stress theory, research on the role of social support in adjustment to loss has focused exclusively on testing the buffering against the main effect model. As Cohen and Wills (1985) argued in their influential review of the literature on social support, such tests require a factorial design that includes at least two levels of stress and two levels of social support. Thus, to test whether social support buffers individuals against the negative impact of the loss of a marital partner, one has to compare the impact of social support in bereaved and married samples. Buffering effects would be reflected by a statistical interaction of social support with marital status on health.

In our earlier review of the literature on social support and bereavement up to 1986 (W. Stroebe \& M. Stroebe, 1987), we found no studies that satisfied these criteria. In the meantime, a

\footnotetext{
${ }^{1}$ These ideas for $m$ the basis of the analysis that the optimal matching theory of Cutrona and Russell ( 1990, p. 330) offers for the role of social support in ameliorating the impact of bereavement. Although matching theories of social support are still rooted in the cognitive stress framework, they stress the importance of matching the characteristics of stressful events confronting an individual and the specific form of social support that is most beneficial in this context. Buffering effects are thus restricted to situations where the social support available is matched to the specific support needs elicited by the stressful event.
} 
few studies using adequate designs, comparing the impact of levels of social support in bereaved samples to that of married controls, have been published. The results are not unanimous in favor of buffering. Although some do indeed report evidence of buffering (Krause, 1986; Norris \& Murrell, 1990; Schwarzer, 1992), albeit using measures of social integration or received social support, others do not (Greene \& Feld, 1989; Murphy, 1988).

Krause (1986) studied the impact of life stresses and social support on depressive symptoms in a random sample of 351 individuals older than 65 living in Galveston, Texas. Social support was assessed with a modified version of the Inventory of Socially Supportive Behaviors ( ISSB; Barrera, Sandler, \& Ramsay, 1981). Depressive symptomatology was assessed with the Center for Epidemiology Studies Depression Scale (CES-D; Radloff, 1977). Whereas no buffering effects occurred for the overall indicator of stressful life events, buffering was found for the numerically undefined subgroup of individuals who had been bereaved within the previous year. These buffering effects modified weak bereavement main effects.

As part of a larger study of individuals aged 55 and older, Norris and Murrell (1990) obtained interviews of three samples of older adults: 45 persons who had recently lost a spouse, 40 who had lost a parent or child, and 45 who were not bereaved. Depression was assessed with the CES-D. Social support was measured with the Louisville Social Support Scale (Norris \& Murrell, 1987), which consists of two subscales reflecting social integration, or embeddedness in a social network, and "expected help." Expected help "taps the respondent's more specific expectations of help in an emergency from family, friends, and community" (p. 431) and thus appears to reflect aspects of perceived social support. Whereas expected help had no impact on depression, an ameliorative effect of social embeddedness on depression was reported. The more individuals were embedded in their social networks, the less they were depressed 9 months after their loss. This association between social embeddedness and depression was stronger for the widowed sample than for a combined control group consisting of individuals who were either nonbereaved or had lost a parent or child.

Schwarzer (1992) studied a sample of 248 individuals above the age of 60 , of which 152 had lost a family member or a friend within the previous year. Social support was defined in terms of visits by children and family members. The criterion measure in this study was anxiety, assessed with a German version of the State-Trait Personality Inventory (Schwarzer \& Schwarzer, 1983). When the sample was dichotomized into those who were visited at least every other week and those who received fewer visits, a clear buffering effect was observed, with loss having no impact on anxiety for individuals who received many visits but a strong impact on those who received few visits.

One puzzling feature of these studies is that buffering effects were observed for measures of social support that typically do not yield buffering effects. According to Cohen and Wills (1985), buffering effects ought only to be found with measures of perceived social support but not with network measures or scales assessing received social support. In contrast, the above studies report buffering effects with measures of social network (Krause, 1986) or received social support (Norris \& Murrell, 1990; Schwarzer, 1992). The one study that assessed both social embeddedness and perceived social support did not find any effects for perceived social support (Norris \& Murrell, 1990). It is plausible that this discrepancy has something to do with the fact that that study included only elderly individuals, a subgroup for whom the needs and provision (and consequently perhaps, perceptions) of social support are very different from those of younger groups.

Two studies, both using samples of more long-term bereaved, did not find buffering effects. In a follow-up assessment of 49 family members and close friends of 51 adult disaster victims of the Mount Saint Helens volcano eruption conducted 3 years after the disaster, in which their mental distress (measured with the Symptoms Checklist-90-R, SCL-90-R; Derogatis, 1977) was compared with that of a nonbereaved control group, there was no evidence of main or buffering effects (Murphy, 1988). Social support was measured with an index developed by Coppel (1980) that assesses social embeddedness as well as perceived social support.

Greene and Feld (1989) examined the relationship between social support and well-being in groups of 151 married women and 60 widowed women who had lost their partner within the previous five years. Respondents were drawn from a national sample of women aged 50 and older. Social support was assessed in terms of the number of social support functions for which respondents mentioned one or more social supporters. Well-being was measured with the Bradburn Affect Balance Scale (Bradburn, 1969). The buffering effect of social support on well-being was estimated by testing the differences in the relevant regression coefficients for widows versus married women. Although only marginally significant, there appeared to be a reverse buffering effect, with widows who had more social support reporting more negative affect.

In summary, the pattern that emerges from our review of research that used adequate designs to study buffering effects of social support in bereavement is not very conclusive. Although there is some evidence of buffering effects, it is limited to elderly samples and to the use of measures typically not associated with buffering in the general social support literature (Cohen \& Wills, 1985). Furthermore, some studies also failed to find buffering effects, although this could be due to the fact that these studies used samples of longer-term bereaved individuals.

\section{The Tübingen Longitudinal Study of Bereavement}

To test predictions of stress theory against attachment theory, an in-depth, longitudinal study of a matched sample of recently bereaved and married men and women was conducted. Perceived social support was measured at the first time wave with a newly constructed questionnaire measure, the Perceived Social Support Inventory (PSSI). This was a German-language scale similar in many ways to the Interpersonal Support Evaluation List (ISEL; Cohen, Mermelstein, Kamarck, \& Hoberman, 1985). Social support was related to depressive and somatic symptomatology assessed at three points in time. Social and emotional loneliness were also measured at the first time point.

The design of our study has thus three important features that distinguish it positively from the majority of earlier studies of the buffering effect: First, instead of using a cumulative index of reported life events as a measure of stress, a specific life event is used that is verifiable, datable, and listed as the most stressful 
event on the Social Readjustment Rating Scale (Holmes \& Rahe, 1967). Second, the use of a longitudinal design with three points of measurement allows the assessment of the impact of social support on both stress vulnerability and recovery from the stressful event. Third, the assessment of two types of loneliness as potential mediators of the impact of bereavement on symptomatology allows for a test of stress versus attachment theory that is independent of the occurrence of a buffering effect.

\section{Method}

\section{Sample}

Widowed and married individuals under the age of retirement, drawn from several towns in southern Germany, participated in the study. Names and addresses of all persons in this age category who had been maritally bereaved 4-7 months previously were supplied by the local registrars' offices. Bereaved individuals were sent a letter describing the nature of the study and asking for their cooperation. No pressure was put on persons to participate if they were reluctant to do so. Those who did not decline participation by mail or phone were then contacted a few days afterward to arrange an interview. This procedure was continued until 30 widows and 30 widowers (mean age 53.05 years) had agreed to participate.

A comparison group of 30 married women and 30 married men (mean age 53.75 years) were individually matched to the widowed persans by sex, age, socioeconomic status, number of children, and town of residence. The comparison group was recruited from addresses of a larger number of matched individuals supplied by the registration offices of these towns. Letters were sent to these married persons, explaining that the study focused on the relationship between marital sta- tus and quality of life. Otherwise, the same procedure was followed as with the widowed group.

To achieve a sample size of 60 widowed persons for the interviews, 217 persons were approached. Of those who refused to participate in an interview, 24 were willing to fill out a mailed questionnaire containing some of the health measures. This allowed us to estimate the impact of selection on adjustment to loss (for a report, see M. Stroebe \& W. Stroebe, 1989). Although the general level of acceptance was rather low, these rates are typical for research in this area (M. Stroebe \& W. Stroebe, 1989). Of the individuals who agreed to be interviewed, $82 \%$ of the widowed and $90 \%$ of the married persons participated in all three interviews. There was no significant health difference between those who participated in all three sessions and those who dropped out.

\section{Times of Measurement}

The participants were inter viewed three times. The first interview was conducted 4-7 months after the loss and the second approximately 14 months after the loss. The third and final interview took place approximately 1 year after the second interview, that is, just over two years after the loss.

\section{Procedure}

Data collection was based on structured interviews as well as selfreport scales. The first two interviews were extensive and held at the homes of the interviewed. The third interview was shorter and conducted over the phone. At the end of each interview, participants were given (after face-to-face interviews at Times 1 and 2) or sent (following a telephone interview at Time 3 ) a questionnaire containing the health measurcs. They were asked to fill out this questionnaire within the following few days and to return it by mail. At Time 1 , the questionnaire

Table 1

Means and Standard Deviations of the BDI and BL by Marital Status, Social Support, and Time for Individuals Who Participated in All Three Interviews

\begin{tabular}{|c|c|c|c|c|}
\hline \multirow{2}{*}{$\begin{array}{l}\text { Variable } \\
\text { and time }\end{array}$} & \multicolumn{2}{|c|}{ Married } & \multicolumn{2}{|c|}{ Widowed } \\
\hline & Low support & High support & Low support & High support \\
\hline \multicolumn{5}{|l|}{$\mathrm{BDI}^{\mathrm{a}}$} \\
\hline \multicolumn{5}{|l|}{ Time 1} \\
\hline$M$ & 5.27 & 4.32 & 10.58 & 9.41 \\
\hline$S D$ & 5.87 & 4.62 & 9.06 & 5.53 \\
\hline \multicolumn{5}{|l|}{ Time 2} \\
\hline$M$ & 7.09 & 3.87 & 8.54 & 8.14 \\
\hline$S D$ & 6.38 & 4.90 & 8.58 & 7.25 \\
\hline \multicolumn{5}{|l|}{ Time 3} \\
\hline$M$ & 6.14 & 3.97 & 7.31 & 6.73 \\
\hline$S D$ & 6.27 & 4.26 & 8.33 & 6.06 \\
\hline$N$ & 22 & 31 & 26 & 22 \\
\hline \multicolumn{5}{|l|}{$\mathbf{B L}^{\mathrm{a}}$} \\
\hline \multicolumn{5}{|l|}{ Time 1} \\
\hline$M$ & 17.05 & 15.13 & 25.48 & 20.55 \\
\hline$S D$ & 9.20 & 11.33 & 17.40 & 13.83 \\
\hline \multicolumn{5}{|l|}{ Time 2} \\
\hline$M$ & 18.73 & 14.26 & 20.78 & 18.09 \\
\hline$S D$ & 10.14 & 11.35 & 15.70 & 13.66 \\
\hline \multicolumn{5}{|l|}{ Time 3} \\
\hline$M$ & 17.96 & 15.16 & 19.48 & 15.96 \\
\hline$S D$ & 11.76 & 12.58 & 16.45 & 10.31 \\
\hline$N$ & 22 & 31 & 27 & 22 \\
\hline
\end{tabular}

Note. $\mathrm{BDI}=$ Beck Depression Inventory; $\mathrm{BL}=$ Beschwerdenliste.

a Higher means indicate higher levels of symptomatology. 
also contained the measure of perceived social support and of the two types of loneliness. All participants returned the questionnaire, but a few failed to respond to all the items. If more than $20 \%$ of the items of a given scale had not been completed, the scale was eliminated from analysis.

\section{Measures}

Perceived social support was assessed at Time I with the PSSI. The PSSI consists of 20 items that reflect four different functions of social support (instrumental, appraisal, emotional, social contact). Participants have to indicate in a true-false (T-F) format whether they have a person who, if the need arose, would provide them with one of the four kinds of support (e.g., "If I could not go shopping, I would have somebody who would do the shopping for me" [instrumental]. "If I would need advice on financial matters, I would have somebody whom I could rely on" [appraisal]. "I have nobody with whom I could talk about my feelings and problems" [emotional, negatively keyed]. "I have hardly any friends who share my interests" [contact, negatively keyed]). Since the four subscales assessing the different support functions are highly correlated with each other, only the overall score was used. The PSSI has high internal consistency $(\alpha=0.90)$.

Loneliness was assessed at Time 1, with two short scales constructed to assess the two types distinguished by Weiss (1982) using a T-F format. The measure of emotional loneliness consisted of the following two items ("I feel lonely even when I am with other people"; "I often feel lonely"). On the basis of the total sample, $\alpha=0.78$ at Time 1 . Social loneliness was also assessed with two items ("l have a really nice set of friends"; "I have friends and acquaintances with whom I like to be together"). At Time 1, $\alpha=0.79$. The correlation between the two scales was . 26

Psychological symptoms were assessed at all three points in time with two measures: a measure of depression and one of somatic complaints. Depressive symptomatology was assessed with the German version of the Beck Depression Inventory ( BDI; Beck, 1967; Kammer, 1983). The BDI consists of 21 items that assess the major symptoms of depression (e.g., sleep and appetite problems, self-reproach, loss of interest in everyday activities) with a multiple-choice format. Since pretests had shown that recently bereaved people resented having to respond to the "lack of sexual interest" item contained in the BDI, it was eliminated from the scale. Somatic complaints were assessed by a symptoms checklist (Beschwerdenliste, BL; von Zerssen, 1976), which is widely used in Germany and has high reliability. The BL lists 24 somatic complaints (e.g., dizziness, difficulty in swallowing, indigestion, excessive sweating, restlessness, neck and shoulder pain). Respondents indicate the extent to which they suffer from each symptom on a 4-point scale $(0=$ not at all; $3=$ very much). The total score is the sum of these points.

\section{Results}

\section{Impact of Marital Status and Social Support on Symptomatology}

Table 1 presents the means and standard deviations of the BDI and BL scores of married and widowed individuals who participated in all three interviews and are below or above the median in their scores on the PSSI measured at Time $1 .^{2,3}$ A 2 (Social Support) $\times 2$ (Marital Status) $\times 2$ (Gender) $\times 3$ (Time) ANOVA (with time as a within factor) conducted on the BDI scores yielded main effects of social support, $F(1,93)=4.33, p$ $<.05$; marital status, $F(1,93)=4.95, p<.05$; gender, $F(1,93)$ $=7.45, p<.01$; and time, $F(2,186)=5.10, p<.01$. Individuals with high social support had lower BDI scores than those with low social support, married persons had lower scores than the widowed persons, and men had lower scores than women. The time main effect, a decrease in depression over time, was modified by the expected Time $\times$ Marital Status interaction, $F(2$, $186)=7.43, p<.001$. Whereas symptom levels of the bereaved persons decreased over time, those of the married persons showed little change. There was also a marginally significant Gender $\times$ Time interaction, $F(2,186)=2.95, p<.10$, with men improving more over time than women. There was no indication of a buffering effect: Neither the Social Support $\times$ Marital Status interaction $(F<1)$ nor the Social Support $\times$ Marital Status $\times$ Time interaction $(F<1)$ approached an acceptable level of significance.

The same analysis conducted on the BL resulted in a similar pattern. There were again main effects of social support, $F(1$, $94)=4.28, p<.05$; gender, $F(1,94)=6.76, p<.05$; and time,

\footnotetext{
${ }^{2}$ Cohen and Wills ( 1985 ) strongly recommend analyzing social sup-
} port data with hierarchical linear regression procedures with the crossproduct term (Marital Status $\times$ Support) forced into the equation after the main effect terms for marital status and support (e.g., Cohen \& Wills, 1985 ) rather than using ANOVA or MANOVA. Regression avoids the loss of information that results from the need to divide the continuous social support variable into categorical data (e.g., median split) in order to use it as an independent variable in the MANOVA. However, our study differs in a number of respects from those reviewed by Cohen and Wills (1985), which makes the use of MANOVA preferable for our data: (a) Roughly $90 \%$ of the studies reviewed by Cohen and Wills (1985) assessed stress using cumulative life event measures. By having also to dichotomize (or trichotomize) the stress measure for the ANOVA in addition to the measure of social support, further loss of information occurred. Our study uses a stress measure that is already dichotomous (i.e., marital status). (b) Most of the studies reviewed by Cohen and Wills (1985) were cross-sectional. The few longitudinal studies reported used only two times of measurement. Thus, buffering in the cross-sectional studies could be tested in the course of one hierarchical regression analysis. (In the case of two time points, buffering was usually tested at Time 2, using symptomatology at Time 1 as the control variable). Our study has three points of measurement. Thus, using a repeated measures design, the MANOVA allowed us to analyze the impact of social support on adjustment measured at three points in time within the same design, whereas regression procedures would have required separate analyses for each point in time. We therefore argue that the added power of the repeated measures design more than compensates for the loss incurred in converting the continuous social support variable into categorical data. Furthermore, if the six regression analyses necessary to test for buffering for the two dependent measures at the three points in time are calculated, there is no evidence of a Social Support $\times$ Marital Status interaction on either measure at any time point. We present the relevant outcomes of the analyses conducted at the first point of measurement as an example, because soon after the loss one would most likely expect a buffering effect: When the interaction of marital status and social support is forced into the equation in a second step (after the main effects of gender, marital status, and social support have already been entered), the interaction is associated with $F<1$ for both the $\mathrm{BDI}$ and the $\mathrm{BL}$. The $R^{2}$ change due to the interaction is .0024 for the BDI and .0004 for the BL. Thus, the buffering effect accounts for less than $0.2 \%$ of the variance of the BDI, and less than $0.04 \%$ of variance of the BL.

${ }^{3}$ The median was at 18 . Scores on the PSSI of 18 and below fell below the median. The mean values of the PSSI for the widowed ( $M=15.29$, $S D=5.26)$ were significantly lower than for the married $(M=18.00$, $S D=2.87), t(1,100)=-3.27, p<.001$. The lower level of social support experienced by the bereaved reflects the support deficit due to the loss of the partner. 
Table 2

Means and Standard Deviations of Emotional and Social Loneliness by Marital Status and Social Support

\begin{tabular}{lccccc}
\hline & \multicolumn{2}{c}{ Married } & & \multicolumn{2}{c}{ Widowed } \\
\cline { 2 - 3 } \cline { 5 - 6 } $\begin{array}{c}\text { Type of } \\
\text { loneliness }\end{array}$ & Low support & High support & & Low support & High support \\
\hline Emotional & & & & 1.27 & \\
$M$ & 0.21 & 0.03 & & 1.17 \\
$S D$ & 0.51 & 0.17 & & 0.83 & 0.87 \\
$N$ & 24 & 35 & & 34 & 24 \\
Social & 0.54 & 0.17 & & 0.77 & 0.24 \\
$M$ & 0.83 & 0.51 & & 0.88 & 0.60 \\
$S D$ & 24 & 36 & 35 & 25 \\
$N$ & & & &
\end{tabular}

${ }^{a}$ Higher scores indicate greater loneliness.

$F(2,188)=4.59, p<.05$, with high social support individuals and men having lower BL scores than low social support individuals and women, and with somatic symptoms decreasing over time. As before, the time main effect was moderated by a Marital Status $\times$ Time interaction, $F(2,188)=7.62, p<.001$, reflecting the fact that there was more change over time for the bereaved than the married persons. There was also the unexpected Gender $\times$ Time interaction, $F(2,188)=3.25, p<.05$, with men improving faster over time than women. There was no indication of a buffering effect: Neither the Social Support $x$ Marital Status interaction $(F<1)$ nor the Social Support $X$ Marital Status $\times$ Time interaction $(F<2)$ approached an acceptable level of significance.

\section{Loneliness as a Mediator of the Impact of Marital Status and Social Support on Symptomatology}

Table 2 presents the scores on the two measures of loneliness taken at Time 1 of married and widowed individuals who are above or below the median in their scores on the PSSI measured at Time 1. A 2 (Social Support) $\times 2$ (Marital Status) $\times 2$ (Gender) ANOVA on emotional loneliness revealed a highly significant main effect of marital status, $F(1,109)=81.65, p<$ .001 , but no significant main effect of social support. The same ANOVA on social loneliness resulted in the complementary pattern, with the main effect of social support becoming highly significant, $F(1,112)=10.36, p<.01$, but not the main effect of marital status $(F<2)$. Thus, consistent with attachment theory, marital status affected emotional loneliness but not social loneliness, whereas social support affected social loneliness but not emotional loneliness.

The analysis of the role of social and emotional loneliness as mediators of the impact of social support and bereavement on symptomatology suggests the reason our study failed to find a buffering effect of social support. According to Baron and Kenny (1986), a variable functions as a mediator when it meets the following three conditions: (a) Variations in the levels of the independent variable significantly account for variations in the presumed mediator, (b) variations in the mediator significantly account for variations in the dependent variable, and finally (c) if the mediator is statistically controlled for, the effect of the independent on the dependent variable is substantially reduced or even eliminated.
To test for mediation, the following three regression models were estimated: First, the assumed mediator was regressed on the independent variable; second, the dependent variable was regressed on the independent variable; and third, the dependent variable was regressed on the independent variable, controlling for the assumed mediator by entering the mediator first in a hierarchical regression analysis. Because the assumed mediator was assessed at Time 1, whereas the two dependent variables were measured at Times 1,2, and 3, only the last two regression models could be estimated for all three points in time (Tables 3 and 4).

Results were fully consistent with predictions from the DualPath Model. First, marital status had a highly significant effect on emotional loneliness ( Table 3 ). Second, replicating the results of the earlier MANOVAs, the impact of marital status on depressive and somatic symptomatology was highly significant

Table 3

Impact of Marital Status on Mediator and Symptomatology

\begin{tabular}{|c|c|c|c|c|}
\hline Variable and time & $\beta$ & $R^{2}$ & $F$ & $d f$ \\
\hline \multicolumn{5}{|l|}{ Emotional loneliness } \\
\hline Time 1 & .66 & .44 & $89.26^{* * *}$ & 1,115 \\
\hline \multicolumn{5}{|c|}{ Depressive symptomatology (BDI) } \\
\hline Time 1 & -.44 & .19 & $28.30^{* * *}$ & 1,117 \\
\hline Time 2 & -.30 & .09 & $10.70^{* *}$ & 1,110 \\
\hline Time 3 & -.17 & .03 & 3.00 & 1,99 \\
\hline \multicolumn{5}{|l|}{ Somatic complaints (BL) } \\
\hline Time 1 & -.29 & .08 & $10.33^{* *}$ & 1,116 \\
\hline Time 2 & -.18 & .03 & 3.63 & 1,110 \\
\hline Time 3 & -.07 & .01 & 0.53 & 1,101 \\
\hline \multicolumn{5}{|c|}{ Controlling for emotional loneliness } \\
\hline \multicolumn{5}{|c|}{ Depressive symptomatology (BDI) } \\
\hline Time 1 & -.15 & $.01^{\mathrm{a}}$ & $2.07^{b}$ & 2,113 \\
\hline Time 2 & -.02 & $.00^{\mathrm{a}}$ & $0.86^{\mathrm{b}}$ & 2,106 \\
\hline Time 3 & .16 & $.01^{\mathrm{a}}$ & $1.64^{\mathrm{b}}$ & 2,96 \\
\hline \multicolumn{5}{|l|}{ Somatic complaints (BL) } \\
\hline Time 1 & .06 & $.00^{\mathrm{a}}$ & $0.31^{\mathrm{b}}$ & 2,113 \\
\hline Time 2 & .16 & $.01^{\mathrm{a}}$ & $1.71^{\mathrm{b}}$ & 2,106 \\
\hline Time 3 & .25 & $.03^{\mathrm{a}}$ & $3.70^{\mathrm{b}}$ & 2,97 \\
\hline
\end{tabular}

Note. $\mathrm{BDI}=$ Beck Depression Inventory $\mathbf{B L}=$ Beschwerdenliste.

${ }^{* *} p<.01{ }^{* * *} p<.001$

${ }^{a} R^{2}$ change.

${ }^{b} F$ change. 
at Time 1, but weakened over time and did not reach significance at Time 3, suggesting that recovery had progressed. Third, when we controlled for the effect of emotional loneliness by entering it first into the regression, the impact of marital status on symptomatology was reduced to zero.

Obviously, the reduction was most impressive at Time 1, when the impact of marital status on symptomatology was substantial, accounting for $19 \%$ (BDI) and $8 \%$ (BL) of the variance. But even at Time 2, where marital status had a highly significant impact on the BDI and a marginally significant impact on the $\mathrm{BL}(p=.06)$, a total reduction in variance due to marital status was achieved by the introduction of emotional loneliness into the regression. According to Baron and Kenny (1986), perfect mediation is indicated by the fact that the impact of marital status on symptomatology is totally eliminated when controlling for the mediator. At Time 3 marital status no longer has a significant impact on symptomatology, thus preventing tests of the mediator role of emotional loneliness at this time point.

Analyses on the mediator role of social loneliness were also consistent with theoretical predictions. Social support had a highly significant effect on social loneliness (Table 4). Furthermore, the impact of social support on depressive and somatic symptomatology, although strongest at Time 1 , still reaches significance at Time 3. Finally, the introduction of social loneliness into the regression substantially reduced the effect of social support on symptomatology. The fact that at least at Time 1 the social support effect remained significant even when we controlled for social loneliness suggests a case of less than perfect mediation.

\section{Discussion}

The pattern of findings observed in this study is consistent with predictions derived from attachment rather than stress the-

Table 4

Impact of Social Support on Mediator and Symptomatology

\begin{tabular}{lcccc}
\hline Variable and time & $\beta$ & $R^{2}$ & $F$ & $d f$ \\
\hline $\begin{array}{l}\text { Social loneliness } \\
\text { Time 1 }\end{array}$ & -.50 & .25 & $39.03^{* * *}$ & 1,118 \\
Depressive symptomatology (BDI) & & & & \\
$\quad$ Time 1 & -.32 & .10 & $13.30^{* * *}$ & 1,117 \\
$\quad$ Time 2 & -.18 & .04 & $4.07^{*}$ & 1,110 \\
$\quad$ Time 3 & -.20 & .04 & $4.30^{*}$ & 1,99 \\
Somatic complaints (BL) & & & & \\
$\quad$ Time 1 & -.31 & .09 & $12.08^{* *}$ & 1,116 \\
$\quad$ Time 2 & -.17 & .03 & 3.32 & 1,110 \\
$\quad$ Time 3 & -.20 & .04 & $4.39^{*}$ & 1,101 \\
Controlling for social loneliness & & & & \\
Depressive symptomatology (BDI) & & & & \\
$\quad$ Time 1 & -.20 & $.03^{\mathrm{a}}$ & $3.96^{* \mathrm{~b}}$ & 2,116 \\
$\quad$ Time 2 & -.07 & $.00^{\mathrm{a}}$ & $0.53^{\mathrm{b}}$ & 2,109 \\
$\quad$ Time 3 & -.05 & $.00^{\mathrm{a}}$ & $0.19^{\mathrm{b}}$ & 2,98 \\
Somatic complaints (BL) & & & & \\
$\quad$ Time 1 & -.25 & $.05^{\mathrm{a}}$ & $6.16^{* \mathrm{~b}}$ & 2,115 \\
$\quad$ Time 2 & -.06 & $.00^{\mathrm{a}}$ & $0.35^{\mathrm{b}}$ & 2,109 \\
$\quad$ Time 3 & -.09 & $.01^{\mathrm{a}}$ & $0.74^{\mathrm{b}}$ & 2,100 \\
\hline
\end{tabular}

Note. $\quad \mathrm{BDI}=$ Beck Depression Inventory; $\mathrm{BL}=$ Beschwerdenliste.

${ }^{*} p<.05 .^{* *} p<.01{ }^{* * *} p<.001$.

$R^{2}$ change.

${ }^{\mathrm{b}} F$ change. ory. The analyses of the impact of social support and marital status on symptomatology revealed main effects for perceived social support and marital status on both the BDI and BL, but no indication of any buffering effects. Individuals who perceived the social support available to them as high reported less depressive and somatic symptomatology than individuals who perceived the availability of social support as low. Similarly, the bereaved persons had higher symptom levels than the married persons.

The design of our study allowed two ways for a buffering effect to emerge, namely, either as a Social Support $\times$ Marital Status interaction or as a Social Support $\times$ Marital Status $\times$ Time interaction. The Social Support $\times$ Marital Status interaction should have resulted if social support protected bereaved persons against the deleterious impact of the loss experience (i.e., the vulnerability factor). Then, highly supported bereaved persons should be less affected by the loss experience than unsupported persons, whereas these differences in social support should have little impact on married persons. If, rather than protecting bereaved persons, social support helped them to adjust more readily to their loss experience (i.e., the recovery factor), the immediate impact of social support should be similar for high and low support groups, but over time, highly supported bereaved persons should recover more readily from the loss experience than the less highly supported (Social Support $\times$ Marital Status $\times$ Time interaction ). Contrary to these expectations, the presence or absence of social support had no greater impact on symptom levels of the bereaved than of the married persons at any time. In none of these analyses was there any indication of a buffering effect. There is even some suggestion of a reverse buffering effect in the pattern of means for the BDI at Times 2 and 3.

Because the discussion of buffering versus main effects in social support has been surrounded by a great deal of controversy regarding the use of regression versus analysis of variance procedures, our choice of MANOVA is justified in Footnote 2 as the most appropriate procedure given our longitudinal design and the use of a dichotomous stress measure rather than a life event scale. We would also like to point out that the sample we employed was of sufficient size to detect a buffering effect, should it have occurred in our study. Cohen and Wills (1985) reported numerous studies using functional measures that found buffering effects with samples that were smaller than or equal to ours, varying from 64 to 120 subjects (e.g., Cohen $\&$ Hoberman, 1983; Fleming, Baum, Gisriel, \& Gatchel, 1982; Gore, 1978; Monroe, 1983; Paykel, Emms, Fletcher, \& Rassaby, 1980; Surtees, 1980). Of the three bereavement studies that observed a buffering effect, described earlier, Norris and Murrell (1987) had a sample that was similar to ours. Furthermore, in a recent study of the role of social support in buffering the impact of unemployment, Schwarzer, Hahn, and Jerusalem (1994), who also employed a longitudinal design similar to ours, demonstrated highly significant buffering effects of social support (i.e., Employment Status $\times$ Social Support interaction) on symptomatology using a MANOVA with repeated measures. Finally, our chance of finding a buffering effect should have been increased by the fact that the stressor used in our study is reputed to be the most stressful life event (Holmes \& Rahe, 1967).

Why, then, did we fail to find a buffering effect? For a buf- 
fering effect to occur, social support from friends and relatives must to some extent compensate for the support previously received from the lost person. The absence of a buffering effect is thus consistent with predictions from attachment theory, which does not allow for this type of compensation. Furthermore, attachment theory also makes assumptions about the processes that mediate the main effect. As noted above, according to attachment theory, marital status and social support influence well-being by distinctly different pathways, with the impact of marital status being mediated by emotional loneliness and the impact of social support by social loneliness (Figure 1). These hypotheses can be tested independently of whether buffering occurs. To our knowledge, our study provides the first indication that the impact of marital bereavement on health and well-being is mediated by emotional loneliness. Because the impact of bereavement on depressive and somatic symptomatology seems to be totally mediated by emotional loneliness, and because social support from friends and relatives does not seem to alleviate emotional loneliness, no buffering effect could have emerged in our study. Thus, our analysis of the mediating processes provides an additional test of the buffering hypothesis.

Overall, the pattern of findings observed in this study provides persuasive support for the predictions derived from attachment theory that losing a partner means losing a major attachment figure, and that social support from family and friends cannot compensate for this effect. The hypothesis from attachment theory that social support affects symptom levels through a different path, by social loneliness, was also clearly supported. Social support did not reduce emotional loneliness, and control for social loneliness substantially reduced the effect of social support. This pattern is quite consistent with the sentiment expressed by many of the bereaved persons interviewed in our study, who typically explained that, although their friends were a great help, they obviously could not replace the loved one.

\section{References}

Baron, R. M., \& Kenny, D. A. (1986). The moderator-mediator distinction in social psychological research: Conceptual, strategic, and statistical considerations. Journal of Personality and Social Psychology, 51, 1173-1182.

Barrera, M., Jr., Sandler, I. N., \& Ramsay, T. B. (1981). Preliminary development of a scale of social support: Studies on college students. American Journal of Community Psychology, 9, 435-447.

Beck, A. T. (1967). Depression: Clinical, experimental and theoretical aspects. New York: Hoeber.

Bowlby, J. (1969). Attachment and loss. Vol. 1: Attachment. London: Hogarth Press; and New York: Basic Books.

Bowlby, J. ( 1979). The making and breaking of affectional bonds. London: Tavistock.

Bradburn, N. (1969). The structure of psychological well-being. Chicago: Aldine.

Cohen, S., \& Hober man, H. ( 1983). Positive events and social supports as buffers of life change stress. Journal of Applied Social Psychology, 13, 99-125.

Cohen, S., Mermelstein, R., Kamarck, T., \& Hoberman, H. M. (1985). Measuring the functional components of social support. In I. G. Sarason \& B. R. Sarason (Eds.). Social support: Theory, research and applications (pp. 73-92). Dordrecht, The Netherlands: Martinus Nijhoff.

Cohen, S., \& Wills, T. A. (1985). Stress, social support and buffering. Psychological Bulletin, 98, 310-357.
Coppel, D. (1980). The relationship of perceived social support and selfefficacy to major and minor stresses. Unpublished dissertation, University of Washington.

Cutrona, C. E., \& Russell, D. W. (1990). Type of social support and specific stress: Toward a theory of optimal matching. In B. R. Sarason, I. G. Sarason, \& G. R. Pierce (Eds.). Social support: An interactional view (pp. 319-366). New York: Wiley.

Derogatis, L. R. (1977). SCL-90-R: Administration, scoring, and procedures manual-I. Baltimore: Clinical Psychometric Research.

Fleming, R., Baum, A., Gisriel, M. M., \& Gatchel, R. J. ( 1982). Mediating influences of social support on stress at Three Mile Island. Journal of Human Stress, 8, 14-22.

Gore, S. (1978). The effect of social support in moderating the health consequences of unemployment. Journal of Health and Social Behavior, 19, 157-165.

Greene, R. W., \& Feld, S. (1989). Social support coverage and the wellbeing of elderly widows and married women. Journal of Family Issues, 10, 33-51.

Holmes, T. H., \& Rahe, R. H. (1967). The social readjustment rating scale. Journal of $P_{\text {sychosomatic Research, 11, 121-218. }}$

Kammer, D. (1983). Eine Untersuchung der psychometrischen Eigenschaften des deutschen Beck-Depressionsinventars (BDI). Diagnostica, 28, 48-60.

Krause, N. (1986). Social support, stress, and well-being among older adults. Journal of Gerontology, 41, 512-519.

Lazarus, R. S., \& Folkman, S. (1984). Stress, appraisal and the coping process. New York: Springer.

Lopata, H. (1973). Widowhood in an American city. Cambridge, MA: Schenkman.

Monroe, S. M. (1983). Social support and disorder: Toward an untangling of cause and effect. American Journal of Community Psychol ogy, 11, 81-96.

Murphy, S. (1988). Mental distress and recovery in a high-risk bereavement sample three years after untimely death. Nursing Research, 37, 30-35.

Norris, F., \& Murrell, S. (1987). Transitory impact of life-event stress on psychological symptoms in older adults. Journal of Health and Social Behavior, 28, 197-211.

Norris, F. H., \& Murrell, S. A. (1990). Social support, life events, and stress as modifiers of adjustment to bereavement by older adults. $P$ s. chology and Aging, 5, 429-436.

Paykel, E. S., Emms, E. M., Fletcher, J., \& Rassaby, E. S. (1980). Life events and social support in puerperal depression. British Journal of Psychology, 136, 339-346.

Radloff, L. (1975). Sex differences in depression: The effects of occupation and marital status. Sex Roles, 1, 249-265.

Radloff, L. (1977). The CES-D Scale: A self-report depression scale for research in the general population. Applied Psychological Measurement, $1,385-401$.

Sanders, C. M. (1993). Risk factors in bereavement outcome. In M. Stroebe, W. Stroebe, \& R. O. Hansson (Eds.). Handbook of bereavement: Theory, research and intervention (pp. 255-267). New York: Cambridge University Press.

Schwarzer, C. (1992). Bereavement, reccived social support, and anxiety in the elderly: A longitudinal analysis. Anxiety Research, 4, 287 298.

Schwarzer, R., Hahn, A., \& Jcrusalem, M. (1994). Unemployment, social support and health complaints: A longitudinal study of stress in Eastern German refugees (Technical Rep. No. 7). Berlin: Department of Educational Psychology, Humboldt University.

Schwarzer, R., \& Schwarzer, C. (1983). The validation of the German form of the State-Trait Personality Inventory: A pilot study. In H. M. van der Ploeg, R. Schwarzer, \& C. D. Spielberger (Eds.). Advances in test anxiety research, Vol. 2 (pp. 215-221). Lisse, The Netherlands: Swets \& Zeitlinger; and Hillsdale, NJ: Erlbaum. 
Stroebe, M., \& Stroebe, W. (1989). Who participates in bereavement research? A review and empirical study. Omega, 20, 1-29.

Stroebe, W., \& Stroebe, M. (1987). Bereavement and health: The psychological and physical consequences of partner loss. New York: Cambridge University Press.

Stroebe, W., Stroebe, M., Gergen, K., \& Gergen, M. ( 1980). Der Kummer Effekt: psychologische Aspekte der Sterblichkeit von Verwitweten. Psychologische Beiträge, 22, 1-26.

Stroebe, W., Stroebe, M. S., Gergen, K., \& Gergen, M. (1982). The effects of bereavement on mortality: A social psychological analysis. In J. R. Eiser (Ed.). Social psychology and behavioral medicine (pp. 527-560). Chichester, England: Wiley.

Stylianos, S. K., \& Vachon, M. L. S. (1993). The role of social support in bereavement. In M. Stroebe, W. Stroebe, \& R. O. Hansson (Eds.).
Handbook of bereavement: Theory, research and intervention (pp. 397-410). New York: Cambridge University Press.

Surtees, P. G. (1980). Social support, residual adversity and depressive outcome. Social Psychiatry, 15, 71-80.

von Zerssen, D. (1976). Die Beschwerdenliste (BL). Weinhein, Germany: Beltz.

Weiss, R. S. (1975). Loneliness: The experience of emotional and social isolation. Cambridge, MA: MIT Press.

Weiss, R. S. (1982). Issues in the study of loneliness. In L. A. Peplau \& D. Perlman (Eds.), Loneliness: A sourcebook of current theory, research and therapy (pp. 71-80). New York: Wiley.

Received March 10, 1995

Revision received December 8, 1995

Accepted February 7, 1996 